\title{
Encountering, Explaining and Refuting Essentialism
}

Jonatan Kurzwelly, Nigel Rapport, Andrew Spiegel

\begin{abstract}
Essentialism manifests differently in the contemporary world. This is clear from the articles in this special issue. That there is contextual diversity of essentialist forms and functions, and that essentialism is used in multiple ways, leads us to argue that it is ultimately pernicious and always potentially dangerous. That is despite essentialism sometimes manifesting strategically in apparently worthy forms where its mobilisation contributes to efforts to overcome oppressive structures. Having outlined the diversity of essentialist expressions reflected in the articles in the special issue, we then offer a brief historical outline of how social anthropology sustained essentialist thinking, even among canonical thinkers. We examine how Durkheimian theorisations and the traditions to which they gave rise - in particular, assumptions of the singular and homogeneous symbolic classification of society-lent themselves to essentialism. We then consider a Southern Africa example where essentialist social theories contributed to heinous and inhumane political formations. Given our conviction that essentialism always carries a latency to be used for pernicious ends, our concluding section considers more recent social anthropological approaches that might permit an understanding of individuals and society in ways that neither lead to nor need essentialist thinking. They recognise the contradictoriness, flux and incompleteness inherent in social life.
\end{abstract}

Essentialism has long had a bad press, particularly in the social sciences. This has been particularly so in South Africa where the discriminatory policies that produced, underpinned and reinforced colonialism and apartheid were based on essentialist notions that demonised (and demoralised) indigenous people by denigrating them and their cultural practices. Despite essentialist discourse having long been denunciated by social scientists, however, the world has seen its marked revival in politics and public discourses which systematically use essentialism and reductionist representations of the social world and increasingly normalise and generate wide acceptance of essentialist thinking (Stolcke 1995). Much of its recent occurrence has been in the context of mass migrations. It has also been provoked by a global economic slowdown, a concomitant increase in personal precarity, and rapid globalisation which simultaneously challenges nation-state structures with their associated lifestyles and facilitates fundamentalist and essentialist challenges to newly formed global 
structures. The latter include instances of essentialism's mobilisation in anti-colonial and similar struggles against systems and structures perceived as globally and locally oppressive. In short, studies of different types, labels, categories and classes, rationales for and consequences of othering, gain a new urgency within the current global rise of political movements which systematically use essentialism and reductionist representations of the social world. The appeal of such politics reflects a wide 'populist' normalisation and acceptance of essentialist discourses and their resulting policy proposals. Essentialist thinking has also re-emerged in the humanities and social sciences, through scholars ascribing different 'ontologies' or other forms of radical difference to groups of people, or by arguing for essentialism's strategic necessity. Our aim is to understand different forms of essentialism through ethnographic description and comparison and to contest the validity of essentialist thinking.

The articles in this special issue offer examples from various parts of the world, providing contextual understanding of particular uses and meanings of essentialism and of reductionism. They include philosophical conceptualisations of essentialism, considerations of its political uses, the essentialist basis of examples of extremism, and essentialism's role in religious movements as also in international development regimes. Their authors use ethnographic examples to reveal both politicised and quotidian narratives, actions and projects that are all based on essentialist and reductionist assumptions about individuals or social groups. Read together, they offer comparisons and theoretical framings which may help to advance understanding of the contemporary place and role of essentialism and reductionism in individual's lives and in society at large. They also contribute to a long-standing and contentious debate in southern African anthropology.

We consider the phenomenon of essentialism from various angles. Our first section discusses different manifestations of essentialism in the contemporary world, using examples from the other articles in this special issue. ${ }^{1}$ We do that in order to understand different forms, functions and uses of essentialism. We also show that essentialism, while ultimately pernicious, sometimes manifests strategically in apparently worthy forms where its mobilisation contributes to efforts to overcome oppressive structures. Our second section offers a brief historical outline of how some social analysts have fallen prey to essentialist thinking. We examine how the Durkheimian structuralist tradition in anthropology lent itself to essentialism. We then provide a Southern African example showing how essentialist social theory contributed to heinous inhumane political transformations. Given our conviction that essentialism always carries a potential to be used for pernicious ends, our third section considers recent social anthropological approaches that might 
permit an understanding of individuals and society in ways that neither lead to nor need essentialist thinking.

\section{The logic and manifestations of essentialism}

Essentialist thinking manifests in various social contexts and is used to define social boundaries and social and personal identities. We consider how the articles in this special issue address the conceptual fallacies inherent in essentialist claims and further our understanding of the different forms, functions and uses of essentialist discourse.

\section{The fallacy of essentialism}

Jacorzynski (2020) demonstrates the fallacy of essentialism by tracing essentialist thinking back to classical Greek philosophy. He outlines Socrates' and Plato's explanation of essence as what is proper to a thing or a substance, its intrinsic 'nature'-its quiddity. Classical Greek philosophers saw essence as the necessary characteristics of a thing (those it cannot lose without ceasing to be itself), as opposed to its accidental or possible characteristics (those it happens to have but could abandon without losing its identity as that thing). Contrariwise, Wittgenstein's attempt to find the essences of abstractions like 'game' or 'time' concluded that that is impossible to achieve because those as other such abstract concepts' characteristics are necessarily context dependent and should not therefore be regarded as static. In other words, there is no neat set of cross-contextually persistent characteristics of a thing, a word, a concept — a social identity or category — that constitutes an essence across all contexts.

Essentialism as used in this collection relates to its social uses. It refers to processes of allocating groups or individuals to social categories, with ascribed characteristics. Essentialism considers such characteristics to constitute the necessary defining properties of people, rather than seeing them as accidental, historical or fictional and changeable characteristics wrought by symbolic constructions. ${ }^{2}$ This ascription often leads to stereotyping, reductions of identity, and assumptions that such essentialist categories predict behaviour.

2 In this article we limit our definition of essentialism to processes of ascribing characteristics to people or objects, characteristics which are then asserted to be necessary and independent of how they are linguistically expressed. Such a definition allows us to operationalise the concept of essentialism to focus on social phenomena and avoid lengthy discussions of the philosophy of language and metaphysics. It also inhibits attributing essences to abstract analytical concepts (e.g. the essence of essentialism) which in this framing becomes a category mistake. Robertson and Atkins (2018) provide an encyclopaedic introduction to ongoing general philosophical debates on essentialism, beyond its applications to individuals and groups of people. 
Yet social categories and identities are used and defined contextually (Okamura 1981; Kurzwelly 2019). No social category is characterised by any single attribute being shared by all its members. This in turn means that seeking the core (essential) characteristics that comprise or define a social identity is a meaningless, fallacious and a potentially dangerous exercise for social analysis. Nonetheless, it is important to understand under what circumstances essentialism manifests and what forms it takes, precisely because essentialising occurs widely and may have socio-political value for those engaging in it.

We begin by considering the articles in this special issue which offer examples of how essentialism fulfils personal existential as well as societal functions.

\section{Enabling individuals to make meaning}

A common function of essentialism is to provide means for people to clarify social identity in order to grasp and give meaning to the world's social complexities. Rapport (2020) shows how essentialist stereotypes — such as of 'British' and 'Britishness' — afford a shorthand for such understanding of the world; that they offer clear-cut symbolic categories, exaggerating both sameness and difference; and that they help demarcate and distinguish between self and others through comparisons and contrast. ${ }^{3}$ Reductions of essentialist stereotypes - however fictional, fallacious - provide clarity and positionality. Furthermore, Rapport argues, such ascriptions of identity afford a sense of hierarchy since clear-cut descriptions of essentialist difference soon lend themselves to prescriptions concerning the value of different identities.

Similarly, Kurzwelly, Fernana and Ngum (2020) argue that essentialism, and especially ideologies which impose a dominance of essentialist thinking and categories in all domains of life, can be attractive; and that that is because such ideologies offer simple interpretative frameworks for making sense of the world, providing relative ease of moral judgements, clear prescriptions for 'proper' behaviour, a potentially positive evaluation of oneself and an increased sense of agency. Their argument is that essentialist thinking and ideologies offer a sense of certainty by helping individuals to mitigate the insecurities resulting from active recognition of the inherent plurality and changeability of oneself and of the social world, and of the related sense of uncertainty, contradictoriness and ambiguity.

Focusing on what philosophers call personal identity, Kurzwelly, Fernana and Ngum

3 Linguistic categorisation in itself risks being reductive and essentialist - "[i]n order to know a man, we see him not in terms of his pure individuality, but carried, lifted up or lowered, by the general type under which we classify him" (Simmel 1971, 8). In that most rudimentary sense, forms of linguistic reductionism and essentialism might seem inevitable. However, not all forms of categorising are necessarily essentialist since only some attribute necessary characteristics to people. 
explain why one cannot assume individuals have an essential personal unity or coherence. They show how, over time, one individual adopted different essentialist identities in order to cope with the exigencies of being a migrant in a xenophobic South African context. They then reflect on his experience to exemplify the usefulness of analytical philosopher Parfit's theory of 'personal identity' (of 'the self'), a theory that sees persons are inherently dis-unified. That disunity manifests not only bodily (e.g. as one ages), but also in one's beliefs, psychological dispositions, tastes and memories, all of which may change over time: there may be nothing like a personal identity fixed through time.

Yet people commonly regard themselves and other individuals as each constituting a lifelong single integrated self. Following Parfit, Kurzwelly, Fernana and Ngum argue that any sense of personal unity is imagined and constructed through 'psychological chains of connectedness' that enable individuals to perceive their own character traits, aesthetic preferences, beliefs, desires and other features - including their social identities - as their continuous defining characteristics. In other words, Kurzwelly, Funana and Ngum conclude, individuals' sense of themselves as personally singular and coherent is formed by their perceiving a cross-contextual continuity of themselves, one that enables individuals to hold an essentialist imaginary of each self, one that meets a societal imperative for individuals to have unified social identities.

\section{Essentialism's political functions}

Another function of essentialism one widely discussed in the literature - is its strategic use to achieve specific broadly political ends. Jacorzynski's (2020) discussion of Polish nationalism provides a telling illustration. He describes several attempts, by Polish nationalists at different historical conjunctures, to find and describe the essence of the Polish nation; and he shows that their respective contexts produced incommensurate ideas about that essence. His discussion of different phases - three historical and one contemporary - of how the Polish nation has been ideologically constructed in essentialist terms provides insight into how much essentialist thinking is and has long been naturalist, theogenic and primordialist ${ }^{4}$ - a characteristic also, as Spiegel (2020) points out, of twentieth century Afrikaner nationalist thinking. Jacorzynski also offers general insight into how a contemporary key political concept - nationality - is often constructed through an essentialist logic and rhetoric that serve reductionist and exclusionary purposes.

4 Primordialism assumes that a social category's characteristics are natural, God-given and have marked the category since the beginning of time. Similar atemporal, or other longue durée assumptions are common to various essentialist expressions - attributing a primordial character of an ethnic group or to supposedly evolutionarily determined femininity. As indicated in a previous note, however, and despite many essentialists asserting such atemporality, not all forms of essentialism are atemporal. 
Niechciał (2020) illustrates a multiplicity of often contradictory ways that a putative group-Zoroastrians - essentialise their identity. Among these are cases where they essentialise for expressly political purposes such as Zoroastrians in Iran, where Zoroastrianism dominated prior to Persia's Islamisation and where the 1979 Islamic Revolution resulted in state-sponsored pressures on non-Muslims to assimilate and convert to Islam. Similarly, Kurds who claim a Zoroastrian preIslamic cultural heritage have converted (or reverted) to Zoroastrianism as a means to emancipate themselves from ISIS-led Islamic domination in Iraq's Kurdistan region. Parsis in India too have essentialised their Zoroastrian identity and constructed strict boundaries around those regarded as Parsis in order to preclude long-accumulated wealth dispersing outside their closed circle.

Despite their common use of essentialism to achieve their respective political ends, Niechciał shows, each example of Zoroastrian essentialism is distinctive: Parsis refer to an hereditary biological essence; Iranian Zoroastrians to a longue-durée cultural essence; and Kurdish Zoroastrians to a lost but nonetheless immanent cultural essence. Niechciał thus demonstrates a plurality of forms for essentialising a social identity within one global religious group.

\section{Essentialism's diverse potential for social damage}

While political essentialism has been widely used to exclude, discriminate against and persecute those considered to be 'Other', not all forms of reductionist discourse are necessarily damaging. Developing a distinction between 'democratic' and 'nihilistic' violence, Rapport (2020) compares essentialism's political use in 'Brexit-era' Britain with that in Nazi Germany. He does that to argue two points. The first is that, while the Brexit discourse surrounding Britain's departure from the European Union may have symbolically violated many Britons' sense of their individuality and selfhood, it did not so severely disrupt everyday social interaction to a point that interaction became physically, emotionally and cognitively impossible, as was often the case in Nazi-era Germany. Indeed, 'democratic' violence may be a universal and 'necessary' feature of society — of individuals bearing embodied ontological differences coming together - and diametrically different from 'nihilistic' violence where the symbolic violence of ascribing individuals and groups particular (reductionist) identities disables social interaction. Since societies accommodate essentialist practices in historically and contextually diverse ways, one should avoid treating all essentialism as necessarily or immediately socially destructive. This is a point that Mathur (2020) also emphasises in her comparison of essentialist expressions by US right wingers regarding what they call the 'white working class' with those of Muslim women in India who essentialised themselves in a struggle both against India's Hindu nationalist government's efforts to disqualify many Muslims from Indian citizenship and thereby also in favour of an inclusivist multiculturalism. 
Although Spiegel (2020) expressly rejects essentialism for its ultimate socially destructive potential, he makes a similar kind of distinction to Rapport's when considering various media narratives about a racialised protest on a Cape Town beach. Arguing that essentialism takes diverse forms, he distinguishes between active essentialism mobilised to restore dignity and renovate practices hitherto forced underground by the hegemony of colonising norms that disdain and denigrate them, and passive forms of essentialist expression. The latter, he says, reflect a sedimentation of culture that renders particular beliefs and behaviours normal and thus comfortable for people to hold and to enact. The passive essentialism of most protesters on the Cape Town beach afforded the enacted ritual the weight the protest leaders needed for mobilising it in their decolonising struggle. Spiegel also asks to what extent apparently white racist media and other online commentary about the incident can be seen as a form of active essentialism, and to what extent it reflects an almost knee-jerk reflex rehearsal of a passive deprecatory essentialism: an attitude also culturally sedimented over time, in part through the influence of volkekunde, an old pro-apartheid form of anthropology.

Rapport's and Spiegel's contributions suggest that we need to distinguish degrees to which manifestations of essentialism are politicised: from relatively harmless non-verbalised or private instantiations, to politically reformist, reactionary, revolutionary or genocidal ones (cf. Phillips 2010). Furthermore, there are degrees to which politicised essentialism mobilises people to action, from passive or democratic to militant, aggressive and violent. Essentialism can be used to disdain and control 'others' from a position of power and privilege, or alternatively used as a tool to fight strategically for the rights of the oppressed or underprivileged.

Rapport's notion of 'democratic essentialism' and Spiegel's of 'passive essentialism' suggest that essentialism is not always, or necessarily, confrontational. Soekoe's (2020) article, based on an ethnography of a rural fishing village in São Tomé and Príncipe (STP), exemplifies. Describing how essentialist notions of underdeveloped people have been adopted by international development-industry actors, by Santomeans working for development organisations and by many STP inhabitants themselves, Soekoe provides examples of what one-might call 'developmental', 'paternalistic' and 'exoticising' essentialism - all of them construing the 'targets' of development as backward, primitive and inadequate -much as colonial administrators did, although now the images validate development interventions. 'Exoticising' essentialism is something for which anthropologists were long criticised; and it remains resonant today in ethno-tourism where essentialism functions simultaneously to valorise and to demean those subjected to the tourist gaze. Sokoe describes how STP's burgeoning NGO-driven tourist industry represents the country STP as a remote, exotic place, located outside time and history. It thereby aims to provide tourists with a 
neutral but voyeuristically interesting perception of difference which is neither necessarily good (or romanticised as such) nor necessarily bad and needing development interventions. In addition, and reflecting an internalisation of hegemonic constructions, Soekoe describes how ordinary Santomeans' own discourse essentialises themselves as backward and needing development interventions to help them break that perceived state.

The above suggests that, at least at the times they occur, manifestations of essentialism vary in terms of their social effects and how one might judge them. Some are pernicious and immediately dangerous - leading to enactments of what Rapport (2020) calls nihilistic violence while others, while quietly culturally disruptive, are neutral - exemplifying democratic violence having mundane, if not immediately positive, socio-cultural consequences.

Finally, it is important to note that the participating actors' motivations in any collective social act of reductionist essentialisation are never the same, even when their goal and the outcome of their actions may be. Citing Devereux's (1978) concept of an 'ego-syntonic' event, in which "[...] any number of very different individual motivations come 'accidentally' to be actualized alike," Rapport $(2020,99)$ makes this point through describing the deployment of apparently diverse but nonetheless essentialist and reductionist depictions of Britishness and European-ness during the UK's Brexit Referendum. Similarly, Spiegel's (2020) analysis of the diverse expressions of essentialism by participants in the beach protest he describes, by the media and by online commentators he quotes, reflects recognition that singular goals can be achieved despite diverse motivations amongst those aiming to achieve them. Phrased more generally, whereas social movements may discursively present their agenda or ideology in essentialist terms, that essentialising form is not necessarily shared by those they mobilise.

\section{Essentialism and social theory}

Essentialism, particularly as a public discourse, risks the pernicious effects of reductionist definitions of identity and of classifications of reality. The risk is exacerbated through identity politics becoming normative so that humans are ordinarily reduced to characteristics attributed to supposedly collective categories, and are fixed as ciphers and scions of reified cultures (Amit and Rapport 2002; Rapport 2012). We return later to suggest how one might escape such 'category thinking'.

Here we recognise the extent to which social science, and anthropology in particular, has itself historically deployed essentialist assumptions. Social-scientific theory, archetypally in Durkheim's work and the various forms of structuralism arising from his thinking, has depended on 
categorising and classifying human actors and deriving their identities, their consciousness and their agency from the collectivities, classes and statuses into which they are categorised.

From Durkheim - as against the transactionalist and materialist approaches of, say, Simmel, Weber and Marx - anthropology in the European tradition and its global variants approached society as a thing-in-itself, a fact, essentially determinant of the individual actors it secured: formative, coercive, homogenising. (Commensurate arguments can be made for the cultural relativism to which Boas's influence gave rise in the North American tradition, and the Völkerkunde to which strains of German-Romanticist thinking gave rise in the ethnological including South Africa's volkekunde - tradition.) A Durkheimian perspective led anthropologists to see humans inhabiting symbolically constructed worlds, classified to reflect consistency in thought and behaviour and where social practices harmonise with and ultimately maintain and reproduce socio- cultural stability and social equilibrium. It thus led to anthropological representations of distinct, bounded and culturally internally coherent societies, each of which has its own distinctive and essential culture.

Durkheim and Mauss (1970[1903]) argued that order in human life is procured through construing and imposing systems of symbolic categories. For them, systems of classification characterise each and every socio-cultural milieux: discrete things are arranged in distinct categories, classes and groups, clearly demarcated and hierarchicalised and standing in fixed relationships to one another whilst united in single, congruous wholes. Such classificatory systems, they argued, are necessary for human understanding because they make intelligible the relations between things; they connect ideas and they unify knowledge. As cultural products, classificatory systems are derivative of, modelled on and expressive of a society and its structure, and they exist for that society's members as social facts, epistemologies: 'natural' and necessary ways of approaching and knowing the world.

Such views were widely shared and undergirded much social-anthropological appreciation of the social-structural ordering of human things. A paradigmatic elaboration was provided by Douglas $(1966,163)$ where she argued that there is a universal human "yearning for rigidity" and a "long[ing] for "hard lines and clear concepts". Moreover, all such classificatory systems and the epistemologies to which they give rise are understood to be anchored to ongoing social realities. From such a perspective, each society represents an homogeneous cultural universe unto itself: members view their social and cultural environments in common as comprising people and things joined and separated by socially sanctioned clear-cut boundaries that must be respected. Here are indubitable, coherent systems from which the contradictory, the incoherent and the arbitrary are banned. 
However, having constructed symbolic classifications of the world, Douglas admits that "we have to either face the fact that some realities elude them, or else blind ourselves to the inadequacy of the concepts" (1966:163). That is, any systemic ordering and classification of matter inexorably rejects certain elements as inappropriate: it must do this in order to arrive at clean lines of division. An inevitable by-product of a system of symbolic classification, therefore, is 'dirt': that which contravenes the ordering. Hedged about with taboo, dirt threatens the world's clear-cut ordering, 'pollutes' its cleanliness, and is therefore eschewed in order to protect cherished principles and categories from contradiction. Yet, while the disorder which pollutedness represents is a threat, it is also recognised as powerful, especially in extraordinary ritual situations. Unrestricted by existing categories and order, it affords new possibilities. Rituals, therefore, represent ventures out of social order and control and attempts to tap an extraordinary power seen as inhering outside everyday human life and belonging to the supernatural. Here, Douglas concluded, is a surmounting of conventional differentiations and a confronting of ambiguity and contradiction: an expression of a common human desire 'to make a unity of all their experience and to overcome distinctions and separations in acts of at-onement' (1966:169).

However, if the human experience universe is purely socio-cultural and necessarily coherent and unitary — as in the Durkheimian view — it is unclear where and how dirty realities intrude, how category edges come to fray and how individuals come to see the contradictory. Seeking to marry Durkheim and Mauss to a Marxian critique making contradiction (via competition and schism) central to the societal model, Gluckman described social systems as replete with ambivalence, as fields of tension, co-operation and struggle (e.g. 1963:135-6). For Gluckman tensions inhered between social-structural organisational principles, institutions and individuals. Nevertheless, these tensions were somewhat controlled through their cathartic expression in ritual. Rituals effected an institutionalised expression of conflict and protest and worked, paradoxically, to renew, strengthen, and even sacralise, established systems. Public statements of rebellion against, and hostilities within, the established social order dramatised conflict and annulments or reversals of hierarchy the normativity of which was reinstated through regular, routine and socially accepted dramatisation. 'Rites of reversal' and 'rituals of rebellion', in short, were extraordinary, topsy-turvy stages which removed the significance and, to an extent, awareness of contradictoriness in ordinary social life thereby dissipating the tensions (social and psychological) generated by these contradictions (Gluckman 1959). Hence, while social systems were no longer conceived of as stable equilibria, at least dynamic equilibria persisted. Leach's (1954) more radical appreciation of this dynamism theorised that this might entail societies in continuous change, swinging, pendulum-like, between contradictory ideal-typical versions of how, symbolically, social life was to be conceived of and lived. 
It remained unclear, however, in the Durkheimian picture, just why recognition and embrace of the contradictory should be cordoned off within ritual's extraordinariness although Turner (1964) sought to explain: If symbolic behaviour creates society, then ritual performances are social groups' dynamic moments when creative practices occur to adjust symbolic creations to pressures for change. The symbols in terms of which rituals are structured provide points of junction, and enable compromises to form, between social needs for classification and control on one side, and innate (anarchic) human drives on the other. Turner theorised that symbolic formulations afford unifications of disparate, contradictory significata; that ritual symbols bring together, in condensed form, what is otherwise divided and kept apart; and that ritual produces societal catharsis and revitalisation of normative social classifications.

In sum, a Durkheimian perspective has societies, as social facts, as things-in-themselves, and as unitary and orderly; that the institutional structuring of societies takes place in noncontradictory fashion; and that individuals, as members of societies, cognitively mirror the institutional structures in which they are habitual role-players. Identity is thus fixed and collectivised: individuals take their places as members of a discrete category or class, a role-player in a social-structural status. They are accorded an essential identity in accordance to their ascribed class or group - lineage, tribe, ethnicity, religion, community, gender, age-grade. Moreover, each society is accorded its own essential cultural identity, its own distinct, coherent (and named) culture, one that determines each individual's identity within it.

\section{African echoes}

Such social-scientific frameworks have often had pernicious political consequences. In the colonial context they were introduced to trainee colonial administrators and used to legitimate the British colonial-governance principle of indirect rule. In the post-colonial African context, explains Nyamnjoh (2017:255), local Eurocentric elites remain "[e]ducated and steeped in the dualisms of colonial ways of knowing and knowledge production". His description of those colonial ways as "epistemologies that tend to privilege neat dichotomies and dualisms, and to caricature, dismember or confine reality to sensory perceptions or to essences" (2017:254) suggests that they exemplify the Durkheimian representations of society outlined above, and that of other similarly taxonomising and essentialising theoretical traditions, such as those that inspired the formation of apartheidserving volkekunde. We offer two particularly infamous examples of stereotypically characterising people: one in essentialist biological terms, another in cultural terms.

The first is Fischer's 1908 physical anthropology research amongst Rehoboth Basters in then 
German South West Africa. Fischer was concerned with "[...] the consequences of race mixture for fecundity, health, vitality, and the 'mental and moral qualities' of a population" (Massin 1996, 123). Using Mendelian genetics, his research aimed to investigate the hereditary transmission of 'pathological characteristics', and to lay foundations for 'racial hygiene' laws preventing racial 'cross-breeding'.

Fischer's 'science' became core to Nazi-era race politics. Hitler drew on Fischer's work to inform his own worldview and referenced it in public speeches. In 1933 Hitler appointed him Rector of Berlin's Friedrich Wilhelm (now Humboldt) University. Later, as director of the Kaiser Wilhelm Institute for Anthropology, Human Genetics, and Eugenics, Fischer developed a Rassenkunde (race science) to serve racist and genocidal politics. Weidenreich's (1946) letter to the editors of Science described Fischer as among "the leading Nazi anthropologists who are morally responsible for the prosecution and extinction of the peoples and races the Nazis considered 'inferior.' [...] If anyone, he is the man who should be put on the list of war criminals." Fischer's and others' pseudo-science was based on eugenicist assumptions that positioned all people, reduced to their essentialised racial categories (both biological and psychological), on a universal scale of superiority and inferiority, ultimately serving as an intellectual basis for genocide. ${ }^{5}$ Fischer's toxic theory had also an impact in Southern Africa, since during his research he was associated with Stellenbosch University (Walters, 2018) where volkekunde was first established.

Malinowski's (1945) attempt to account for what he called culture change includes a second example of the toxicity of a theoretical framework that fixes boundaries around people and essentialises them. It reveals Malinowski's view of 'cultures' as distinctive separate social realities each with its own essential characteristics and each needing protection from external (for Malinowski that meant colonial) influence. He consequently rehearsed an already common argument for the protection, in South Africa, of what were regarded as distinctive and separate cultures and for this to be effected through segregation which would supposedly assure the wellbeing of 'natives'. Malinowski saw equality between Europeans and 'natives' as ultimately impossible, and any belief in it as undesirable:

If, from the outset, it were possible to make quite clear in preaching the gospel of civilization that no full identity can ever be reached; that what are being given to the Africans are new conditions of existence, better adapted to their needs but always in harmony with European requirements, the smaller would be the chances of a strong reaction and the formation of new, potentially dangerous nationalisms. (1945: 160)

These views were reflected in a 1934 lecture in Johannesburg by Malinowski and chaired by

5 For further reading on German race science see Massin 1996; on the Kaiser Wilhelm Institute see Schmuhl 2008; and on German colonial anthropology more generally see Penny and Bunzl 2003. 
then South African Minister of Justice, Jan Smuts. ${ }^{6}$ There Malinowski expressly supported introduction of a segregated education system as a means for 'protecting the natives.' He argued that there were insufficient jobs for educated natives, and that education would lead them to rebel against their tribal authorities and their 'culture'. Gordon (1990) and Niehaus (2017), in their descriptions of these events, affirm that Malinowski's arguments gave intellectual legitimacy to the discriminatory apartheid-era Bantu Education Act and indirectly influenced apartheid.

Malinowski's views as outlined above produced three divergent responses. One, from Gluckman (1947), rejected Malinowski's essentialist perspective as also his policy engagement. Reviewing Malinowski's (1945) book, Gluckman wrote: “His 'theory' does not bear examination from any point of view. It is analytically sterile, and it ends in the worst kind of practical anthropology: welfare work without morality, based on naive oversimplification" (1947: 121).

A second response used the kind of essentialist perspective Gluckman had resisted, albeit also to reject segregation. Hoernlé and Hellmann (1953:34-44), two then senior South African social anthropologists, critiqued the 1951 Report of the Commission on Native Education that, reflecting Malinowski's suggestion, proposed a segregated and distinctive (Bantu) education system. ${ }^{7}$ Arguing for a single education system to prepare everyone "for all the requirements of modern society", Hoernlé and Hellmann's commented that nothing in what the Commission described as "traditional Bantu cultures" provided the foundation for a distinctive and separate "progressive, modern and self-respecting Bantu order of life". This reflected their own essentialist thinking as did their statement that "total assimilation of the knowledge, techniques, standards and values of Western culture by the Bantu" was needed (Spiegel and Becker 2018:4-5). As Sharp (1981) indicated, many South African social anthropologists continued similarly to essentialise, largely, we would argue, because of a persisting Durkheimian influence albeit tinged by Malinowskian or Boasian relativism.

The third response to Malinowski, as Gordon (1990) and Niehaus (2017) have shown, manifested as whole-hearted agreement with both his essentialism and his assertion that indigenous people's cultures should be left as undisturbed as possible. Such agreement came from apartheid ideologues including, as Sharp (1981) and Gordon (1988) demonstrated, anthropologists at Afrikaans-language universities whose disciplinary "preoccupation was to document the cultural essences and their manifestation in belief of each of the supposedly distinctively different peoples (volke) among South Africa's indigenous population" (Spiegel and Becker, 2018:3). ${ }^{8}$ Described as

$6 \quad$ As Mamdani (1996:3-5) reminds us, in a prestigious Oxford lecture in 1929 Smuts had explicitly described African people as essentially child-like.

7 The apartheid regime soon imposed precisely such an education system.

8 The chair of the 1951 Commission on Native Affairs, WWM Eiselen, was the founder, in 1926, of volkekunde at Stellenbosch University (Gordon, 1988). That he subsequently became secretary of Native Affairs for the apartheid 
volkekunde, and drawing on ideas from pre-WWII German Völkerkunde (study of 'other' peoples), and in parallel to Soviet ethnos theory, the volkekunde version of anthropology was presented as a study of singular, unified, and historically persistent and essentialised groups of people (ethnoses; ethnes) and their respective and distinctive cultures which bind members of each ethnos or volk (people) together (Sharp 1981; Gordon 1988). As Spiegel (2020) indicates, and significantly as regards uses of essentialism for political purposes, volkekunde's preoccupation with African people's cultural distinctiveness reflected the obverse side of an increasingly strident Afrikaner nationalism that essentialised Afrikaners and their nation by claiming a distinctive and God-inspired cultural identity ${ }^{9}$ linked to a commitment to ensuring white racial purity. It is thus no surprise that, as Gordon (1988) points out, volkekunde found a ready purchase in Afrikaans-language universities where Afrikaner nationalism was determinedly mobilised.

\section{Strategic essentialism}

The above may be read as implying that essentialist thinking, and policies based on it, are found exclusively in contexts where essentialism is used to dominate. However, as we have shown earlier, essentialism is widespread in popular thought. Moreover, essentialist theorising has not been confined to the grim colonial-serving past of our discipline. Indeed, various scholars, including those explicitly working against colonialism, have argued that essentialism may be useful, even necessary, in struggles against domination and structures of inequality, and towards what may broadly be described as postcolonial and decolonial scholarship. Amongst them are feminists whose extensive debates on the issue as regards gender and sex differences have become a touchstone for much contemporary theorisation of essentialism (e.g. Fuss 1989). Also amongst them are those in what came to be known as Subaltern Studies and who sought to restore the dignity of colonially and post-colonially dominated segments of the population, legitimating a denigrated identity and sanctioning its visibility.

In a widely debated book, Chibber (2013) introduced a cogent critique of Subaltern Studies, arguing that it maintained and even reinforced an 'orientalist' perspective by essentialising a West- East divide. Chibber argued that Subaltern Studies -echoing Levy-Bruhl (1926)'s thesisinsisted that 'Eastern' protagonists think differently from people in the West, that they operate from a different political psychology and are driven by intrinsically different motivations. A consequence, Chibber points out, is that work intended to be radical and to prioritise the subaltern's perspectives ended up reproducing an essentialist orientalism, denying universalism and precluding 
seeing people across geopolitical divides as part of one, often exploitative and polarising human history. Wolfe (2017) raised a similar critique, albeit of decolonial-turn scholarship which, he said, often perpetuates notions of irreconcilable differences. Graeber (2015) too has pointed out similar problems with the so called 'ontological turn' which derives its assertions of radical difference from assumptions about an ontology indistinguishable from classical philosophical idealism. Martin (2019:21) similarly asserts that distinguishing between a Western dualist ontology and an indigenous non-dualist ontology

accepts the fundamental self and other essentialisation set up by civilising national forces and merely inverts it, casting the former good guys of colonial civilisation as the bad guys of colonial oppression and depicting the former bad guys of native superstition as the good guys of noble savageness reborn, fulfilling their age-old role as the mirror in which we can see that civilisation is the apotheosis of humanity's downfall rather than its ascent. It takes the 'clash of civilisations' view so popular amongst Western conservative right-wingers (Huntington, 1996) and rebrands it as a clash of ontologies, in which the opposite of the essential West is recast from being the reactionary enemy of capitalist progress into the progressive enemy of reactionary capitalism.

We evoke this critique of contemporary essentialist theorisation not to argue for a blindness to difference, or to delegitimise the grievances of those who essentialise strategically, but to point out the erroneous logic and potential dangers inherent in essentialism. As Spiegel (2020) points out, it was precisely because Spivak (1993) recognised how easily it could be used to justify pernicious uses of essentialism that she rejected the 'strategic essentialism' couplet that arose from her intervention five years earlier. Yet as various articles in this special issue demonstrate, the concept remains useful for describing and historically contextualising cases where essentialism is used strategically. ${ }^{10}$

A detailed and systematic exploration of past and current theories that perpetuate essentialism warrants a separate discussion. Our goal here has been only to show that there are persistent reasons for vigilance about our scholarly understanding of otherness and difference, especially when it perpetuates category thinking: notions of radical difference between classes of people, and Durkheimian-type assumptions of internal unity of social groups and categories. Ultimately, we believe, it is only through a notion of shared humanity and interconnected world history that contemporary global issues can be successfully analysed.

10 Mathur (2020) eschews the notion in favour of that of critical multiculturalism which she takes from Terence Turner (1993). White (2019) may have intended also to contextualise strategic essentialism in his polemic suggesting a path for anthropology towards a decolonising scholarship and towards decolonising anthropology. Yet the works he cites as evidence of South African anthropologists essentialising in the present, for purposes of valorising and making visible cultural practices that colonialism has deprecated, are insufficiently detailed to support his claim. 


\section{Contradictoriness and incompleteness—against essentialism}

In this final section we make an argument for recognising the intrinsic place of contradiction, incompleteness and plurality in human thought and practice, and hence for eschewing the fallacious assumptions of essentialistic logic as it has been applied to persons' identities and to societies' cultural distinctiveness.

\section{Contrarieties of identity}

The anthropological orthodoxy which began with Durkheim shrouded contradiction by seeing social order as wedded to an everyday eradication of symbolic contrarieties. It denied individuality and idiosyncrasy and failed to regard identity as something complex, inchoate, in flux, always in the process of being perceived, formulated, expressed and reformed-self-contradictory. At best, contradiction was recognised in a Durkheimian formulation as pertaining between states of order and disorder or un-order - between different social-structural episodes, between structure and ritual - but not as a state in itself. Absent from this line of thought was an appreciation of the possible ubiquity of contradiction: individuals saying and doing and thinking inconsistent things as a matter of course; individuals employing multiple, contradictory symbolic classifications at the same time, individuals construing classificatory 'systems' that were in themselves contradictory: identities that were not essentially either/or but both/and (Rapport 1997a).

Nyamnjoh (2017:256) writes: since "[b]oth reality and the universe are imbued with endless possibilities of being...[t]hings, words, deeds and beings are always incomplete, not because of absences but because of their possibilities and becoming". He urges that, as social analysts, we need to recognise incompleteness as a central tenet of social and cultural life and make it central to all our analyses. Nyamnjoh takes his lead from popular African narratives and their representation in works such as Tutoala's (1952) novel, The Palm Wine Drinkard. Here, a man, described as a complete gentleman, attracts the attention of a young woman eager to be associated with him. She follows him through the forest observing how he slowly returns various of his gentlemanly characteristics (physical as well as cultural) to others from whom he has borrowed them, so that he is eventually no more than a skull—one that attempts to draw her into the hole in the ground which is its home. ${ }^{11}$

11 Examples of literary work which raise similar arguments can be found elsewhere but social science has long overlooked them. An example is Gombrowicz's 1937 novel, Ferdydurke, where he described the process of searching for a true essentialist self, free of masks - he calls them 'mugs'. His main character concludes that there is no such thing as a mug-less essential self, that we all adopt different 'mugs' (faces, roles, identities, behaviours...) contextually. "[...] I say hello to you, hello, graceful bundles of body parts, now let it all begin-come, step up to me, begin your kneading, make me a new mug so I will again have to run from you and into other people, and 
Nyamnjoh's point in drawing on this imagery is that everything, including every person, is incomplete and always in process of accreting form, whether materially or social-culturally; and that any image of completeness — of fixed, essentialist and classifiable identity — such as represented by social-scientific thinking as influenced by Durkheim, is thoroughly misplaced. This point is similar to Kurzwelly, Fernana and Ngum's (2020) argument that any sense of a person's persistent unity is imaginary and obfuscates a person's inherent multiplicity. Nyamnjoh's further point is that this insight concerning incompleteness derives from an otherwise widely denigrated and silenced African view of the person that nonetheless has a long history in popular thought. It reflects an epistemology that, had it been taken seriously as such even at the time Tutoala's novel was published, might have helped overcome the neat coalescence in much social science between essentialist thinking and a Durkheimian perspective.

We now turn to some of the reasons that might lead anthropological theorising to turn away from the Durkheimian perspective, and explicitly to embrace notions of contradictoriness, personal, social, cultural, even epistemological (Rapport 1997b). In an influential collection of essays (1990), Berlin elaborated upon the Kantian aphorism that 'Out of the crooked timber of humanity no straight thing was ever made'. It is wrong to expect necessary commensurability, final reconcilability or true synthesis between the supreme values, the true answers and the final ends as construed within the diverse world views of different individuals and societies. 'Great goods' can always be expected to collide precisely because there is no determinate means of putting individuals' and societies' different 'goods' together, no single overarching standard or criterion available to decide between or to harmonize discrete moral registers. Contradiction inheres not merely between a succession of civilizations or nations, persons, times or places, but also within contemporaneous ones.

Anthropologists too have illuminated the contradictoriness of social life, social systems 'at war with themselves' (Douglas 1966:141) and promoting a disharmony of ends for individuals to pursue. As Malinowski (1948 [1922]:194), in a quite different register from that of his later work, urged: "Arguing by the law of logical contradiction is absolutely futile in the realm of belief, whether savage or civilised. Two beliefs, quite contradictory to each other on logical grounds, may co-exist, while a perfectly obvious inference from a firm tenet may be simply ignored". Nor is this only a matter of beliefs. As Leach (1977:11) observed: "When you see what people actually do, as distinct from what they are supposed to, most of the category distinctions which provide an orderly framework for our social thinking tend to disappear". All real social boundaries are fuzzy, and individuals cross them, creolise them, negate them and recreate them, even as the prime function of 
societal norms, laws, customs and conventions - habitus and its institutions and officers - may be to stop them. However much one might endeavour to impose an appearance of universal homogeneity on a society, of systemicism and consensus, empirically such do not exist. 'Any complex society', Leach (1977:28) concluded, is likely to contain "as many distinguishable "systems of customary rules and conventions" as there are individuals". If earlier anthropology eschewed contradiction, this reflected more the axiomatic nature of its own analytical discourse than sociocultural reality.

Strathern (1990:6) similarly argued that to do justice to the 'diversity and multiple character' of phenomena requires analysis of empirical reality that does not reduce to systemic representation but produces anthropological accounts which specify complexity without simplifying it. As Parkin (1987:66) elaborated, anthropology must anticipate the 'limitless discursive perspectives' that human beings might construe: recount the contradictory world-views and life-projects both between individuals in a social setting and also within those individuals. In other words, we should appreciate humans constructing and maintaining a diversity of contemporaneous perspectives for themselves, each contradictory of and incommensurate with others in terms of their constituent elements, relationships, values, norms, desires, expectations. Individuals think, speak and act in any number of contradictory ways (Ewing 1990; Rapport 1993).

This contradictoriness in thought, speech and action may be more and less conscious, and more and less strategic. In some instances, contradiction is disguised by the momentariness of life, by how conscious existence turns on momentary thoughts, feelings, apprehensions, emotions and dwells in the intensity of 'moments of being' (Woolf 1976). In others contradictoriness is employed as a (duplicitous) vehicle for purposive social gain: pleasing an electorate, confusing an enemy, being polite to a guest, keeping in with a friend, insulting, provoking, misleading, mystifying another or oneself. The anthropologist envisages a graded scale, Wolfram suggests (1985:72-3), between blatant and non-blatant, self-evident and fuzzy contradictions, between extremes of intentioned and unintentional contradictoriness.

When the private becomes public and the personal becomes social-when selfcontradictory individuals interact - the situation becomes less simple, coherent or consistent. Interaction between individuals and their variegated cognitions in a social setting does not somehow give rise to homogeneous, consensual, coherent and consistent social systems that are characteristically singular (or systemic). The opposite, in fact, pertains as the contradictoriness of one individual meets that of others; the picture is chaotic: a diversity of perspectives, of symbolic constructions of the world, influence a diversity of others in all manner of indirect, incidental, changeable, distortive — and contradictory—ways (Rapport 2017). 
In short, appreciation of contradiction lead to a modelling of human social life not as something coherent but rather as a muddling through. There is a diversity of contradictory symbolic realities or perspectives in use at any one moment and between moments, even in the 'same' social setting, and there is no necessarily singular, clear, uncontested or coherent relationship among this diversity. Societies are neither systemic nor singular, for they are constituted by the aggregation of a multiplicity of private symbolic-classificatory orders - of personal 'cultures'—which collide, abut, overlap, and need not consistently co-ordinate or coincide. Furthermore, the muddle is neverending, brought on by interacting individuals continuing to influence one another and themselves in all manner of possibly unintentional ways. Social interaction comprises the disorderliness of diversity, inconsistency, distortion and uncertainty rather than an orderly system (cf. Morin 2008).

\section{Populist essentialism}

If, however, anthropological imaginaries have arrived at rather different expectations from the traditional Durkheimian images of singularity, coherency and consistency — of symbolic-cognitive classifications expressing the structural-functional solidarities of their societal origins and where contradictoriness is something extraordinary if not pathological - then this does not negate the continuing mundane attraction of non-contradictory claims and posturings. Essentialism is populist: it has indeed become a kind of 'postmodern religion', in Bauman's (1998) phrasing. If, in societies of increasing complexity and scale, life may be lived in an infinitude of forms, with no overriding guidelines or fixed orientations and no promise of fixed conditions - if the course of a human life is open-ended, a vagary, in which relations are fluid, achievements brittle, values and rules changeable - then one must choose, keep choosing, and not miss an opportunity for choice. But what and how will the individual choose: what definitions of identity make, what judgements exert? How will that identity and those judgments themselves be assessed over time? Bauman suggests that the associated nausea and anxiety has generated a new kind of fundamentalism, strategic and intentioned or otherwise. Born of contemporary life's pluralism, and senses of insufficiency, deprivation, marginality and non-recognition, a post-modern religiosity of a fundamentalistic politics of identity endeavours to deny self-sufficiency and self-reliance. Instead it offers guidance and direction, freedom from choice - and therefore from risk. Here is a fundamentalism, Bauman (1998:67-75) concludes, that promises the infinite powers of an organic collectivity and subordinates each individual member to the needs and rules proclaimed in the collective name. The identity politics of religion, tribe, race and ethnicity, demand alike a reductionism and an essentialism that provide an alternative to abandonment and solitude in the market of choice.

The problems that such postmodern religiosity addresses are real, Bauman admits, but the 
issue is to find other, non-totalitarian solutions. Jackson (2002) concurs arguing that notions of culture, race, tribe, nation, cosmos that emphasise an essentialist belonging reflect widespread anxieties about people's ability to grasp and influence the forces that overwhelm their life-worlds, including people disadvantaged by colonial and postcolonial inequalities. It is ironic, then, that, as anthropology has come to deconstruct such notions, they are popularly embraced and employed, and in "an essentialist, exclusionary sense", for imagined counter-hegemonic ends: people imagining "they can recapture something of the integrity and authenticity they feel they have personally lost" (Jackson 2002:107, 110). But this is seldom all that transpires. As Jackson elaborates, all such collective nouns and identity terms convert individual human subjects of experience into objects of knowledge, reducing and "transmuting the open-endedness and ambiguity of lived experiences" (2002:125) into something determinate and known: instances, examples and expressions of reified categories. A fundamentalist and essentialist deployment of culture, race, tribe, nation and cosmos inevitably entails demarcation, denial, division and exclusion, a world divided into true believers and belongers on one hand and outsiders on the other.

"Any kind of identity thinking is insidious", Jackson concludes, because "like all reification, it elides the line that separates words and worlds, language and life" (2002:115). Reducing the world to simplistic, generalised category oppositions admits neither synthesis nor resolution, and is self-perpetuating, vast areas of human experience becoming suppressed or abolished. Our response must be to annul the language of collective (cultural) essences and the reductionism it spawns. Our response must be to pursue a pragmatist critique of 'culture. The empirical reality of social life is the tension and interplay between individuals and among multiplicities of symbolic classes, categories and systems. We do not ordinarily accord the latter symbolisations a foundational or determinate role. Contradictoriness and incompleteness, the perpetual flux of experience, must remain our bellwether.

\section{References}

Abrahams, R. 1990 'Chaos and Kachin’ Anthropology Today 6(3): 15-17.

Amit, V. and Rapport, N. 2002 The Trouble with Community: Anthropological Reflections on Movement, Identity and Collectivity, London: Pluto.

Bateson, G. and Ruesch, J. 1951 Communication, New York: Norton.

Bauman, Z. 1998 'Postmodern religion?', in P. Heelas (ed.) Religion, Modernity and Postmodernity, Oxford: Blackwell, pp. 55-78.

Berlin, I. 1990 The Crooked Timber of Humanity, London: Murray. 
Chibber, V. 2013. Postcolonial Theory and the Specter of Capital. London: Verso.

Devereux, G. 1978 Ethnopsychoanalysis. Berkeley: University of California Press

Douglas, M. 1966 Purity and Danger, London: Routledge and Kegan Paul.

Durkheim, E. and Mauss, M. 1970 Primitive Classification, London: Routledge.

Ewing, K. 1990 'The Illusion of Wholeness: Culture, Self and the Experience of Inconsistency', Ethos 18: 251-278.

Fuss. D. 1989. Essentially Speaking: Feminism, Nature and Difference. New York, Routledge.

Gluckman, M. 1947 'Malinowski's 'Functional' Analysis of Social Change', Africa: Journal of the International African Institute, 17(2): 103-121.

1959 Custom and Conflict in Africa, Glencoe: Free.

1963 Order and Rebellion in Tribal Africa, New York: Free.

Gordon, R. 1988. 'Apartheid's Anthropologists: The Genealogy of Afrikaner Anthropology', American Ethnologist 15(3) 535-553.

1990. Early social anthropology in South Africa, African Studies, 49(1): 15-48.

Graeber, David. 2015. 'Radical Alterity Is Just Another Way of Saying "Reality": A Reply to Eduardo Viveiros de Castro'. HAU: Journal of Ethnographic Theory 5 (2): 1-41.

Hoernlé, W. and E Hellmann. 1953. An Analysis of Social Change and Its Bearing on Education. Race Relations Journal 20 (4): 33-44.

Jackson, M. 2002 The Politics of Storytelling: Violence, Transgression and Intersubjectivity, Copenhagen: Museum Tusculanum Press.

Jacorzynski, W. 2020. "Persistent essentialism in Polish nationalist discourse: A Wittgensteinian critique." Anthropology Southern Africa 43(2): 82-93.

Kuper, A. 2003. The Return of the Native Current Anthropology 44(3): 389-402

Kurzwelly, J. 2019 'Being German, Paraguayan and Germanino: Exploring the Relation Between Social and Personal Identity', Identity, 19(2): 144-156.

Kurzwelly, J. with Fernana and Ngum 2020. "The allure of essentialism and extremist ideologies." Anthropology Southern Africa 43 (2): 107-118

Leach, E. 1954 The Political Systems of Highland Burma, London: Athlone. 1977 Custom, Law and Terrorist Violence, Edinburgh: Edinburgh University Press.

Lévy-Bruhl, L. 1926. How Natives Think. Translated by Lilian A. Clare. London: George Allen \& Unwin.

Malinowski B. 1945 The Dynamics of Culture Change. An Inquiry into Race Relations in Africa. New Haven: Yale University Press.

1948 Magic, Science and Religion, and other essays, Glencoe: Free Press.

Mamdani, M. 1996. Citizen and Subject: Contemporary Africa and the legacy of late colonialism. 
Kampala, Fountain; Cape Town, David Philip; London, James Currey

Martin, K. 2019 'Subaltern perspectives in post-human theory', Anthropological Theory,

(November 2019). doi:10.1177/1463499618794085.

Massin, B. 1996. 'From Virchow to Fischer: Physical Anthropology and "Modern Race Theories" in Wilhelmine Germany'. In Volksgeist as Method and Ethic: Essays on Boasian Ethnography and the German Anthropological Tradition, edited by George W. Stocking, 79-154. Madison, Wis: University of Wisconsin Press.

Mathur, C. 2020 "Singing about the dark times: Notes on situated understandings in our age of essentialisms." Anthropology Southern Africa 43 (2): 133-142.

Morin, E. 2008 On Complexity, Cresskill NJ: Hampton.

Niechciał, P. 2020 "Essentialism in Zoroastrian Boundary Construction." Anthropology Southern Africa 43 (2): 119-132

Niehaus, I. 2017 'Anthropology at the dawn of apartheid', Focaal - Journal of Global and Historical Anthropology, 77: 103-117.

Nyamnjoh, F. B. 2017 'Incompleteness: Frontier Africa and the Currency of Conviviality', Journal of Asian and African Studies, 52(3): 253-270.

Okamura, J. Y. 1981 'Situational ethnicity’, Ethnic and Racial Studies, 4(4): 452-465.

Parkin, D. 1987 'Comparison as a search for continuity', in L. Holy (ed.) Comparative Anthropology, Oxford: Blackwell, pp. 52-69.

Penny, H. G., and M. Bunzl, eds. 2003. Worldly Provincialism: German Anthropology in the Age of Empire. Social History, Popular Culture, and Politics in Germany. Ann Arbor: University of Michigan Press.

Phillips, A. 2010 'What's wrong with Essentialism?', Distinktion: Scandinavian Journal of Social Theory, 11(1): 47-60.

Prigogine, I. 1989 'The Philosophy of instability’, Futures August: 396-400.

Rapport, N. 1993 Diverse World-Views in an English Village, Edinburgh: Edinburgh University Press.

1997a "The "Contrarieties" of Israel: An essay on the cognitive importance and the creative promise of both/and', Journal of the Royal Anthropological Institute 3,4: 653-72.

— 1997b "Edifying Anthropology: Culture as Conversation: Representation as Conversation", in A. James, J. Hockey and A. Dawson (eds) After Writing Culture: Epistemology and Praxis in Contemporary Anthropology. London, Routledge, pp. 176-93.

— 2000 "Criminals by instinct": On the "Tragedy" of Social Structure and the "Violence" of Individual Creativity', in G. Aijmer and J. Abbink (eds) Meanings ofViolence: A Cross-Cultural Perspective, Oxford: Berg, pp. 39-54. 
2012 Anyone, The Cosmopolitan Subject of Anthropology, Oxford; Berghahn.

2017 (ed.) Distortion: Social processes beyond the structured and systemic, London:

Routledge.

2020. "Britain and Brexit: Imagining an Essentialist Sense of 'Britishness' and Navigating among 'the British." Anthropology Southern Africa 43 (2): 94-106.

Robertson, Teresa, and Philip Atkins. 2018. 'Essential vs. Accidental Properties'. In The Stanford Encyclopedia of Philosophy, edited by Edward Zalta.

https://plato.stanford.edu/archives/spr2018/entries/essential-accidental/.

Schmuhl, H-W. 2008. The Kaiser Wilhelm Institute for Anthropology, Human Heredity, and Eugenics, 1927-1945: Crossing Boundaries. Dordrecht: Springer.

Sharp, J.S. The Roots and Development of Volkekunde in South Africa. Journal of Southern African Studies 8(1):16-36.

Simmel, G 1971 [1908]. 'How is society possible?', in D. Levine (ed.) On Individuality and Social Forms, Chicago: University of Chicago Press.

Soekoe, N. 2020. "Living excluded from the world: Essentialism in development discourse and its percolation into Santomeans' self-perceptions.” Anthropology Southern Africa 43 (2): 156168.

Spiegel, A.D. 2020. "Sheep, herbs and blood on the beach: Discrepant representations of ritual acts for essentialising and reinforcing difference in contemporary South Africa" Anthropology Southern Africa 43 (2): 143-155.

Spiegel, A.D. and H. Becker. 2018. South Africa, Anthropology in. International Encyclopedia of Anthropology. (ed.) Hilary Callan. Wiley-Blackwell

Stolcke, V. 1995. Talking Culture: New boundaries, new rhetorics of exclusion in Europe. Current Anthropology 36(1):1-24.

Strathern, M. 1990. Partial Connections, Savage MD: Rowman and Littlefield.

Turner, T. 1993. Anthropology and Multiculturalism: What Is Anthropology That Multiculturalists Should Be Mindful of It? Cultural Anthropology 8 (4): 411-429.

Turner, V. 1964. 'Symbols in Ndembu ritual', in M. Gluckman and E. Devons (eds) Closed Systems, Open Minds, Chicago: Aldine, pp. 158-261.

Walters, H. 2018. Tracing Objects of Measurement: Locating intersections of race, science and politics at Stellenbosch University. $\mathrm{PhD}$ thesis, Stellenbosch University.

Weidenreich, F. 1946. 'On Eugen Fischer'. Science 104 (2704): 399-399.

White, H. 2019. What is anthropology that decolonising scholarship should be mindful of it? Anthropology Southern Africa 42(2):149-160.

Wolfram, S. 1985. 'Facts and theories: Saying and believing', in J. Overing (ed.) Reason and 
Morality, London: Tavistock, pp. 71-85.

Wolfe, R. 2017. 'Dialectics and Difference: Against the "Decolonial Turn"،. Insurgent Notes:

Journal of Communist Theory and Practice. http://insurgentnotes.com/2017/08/dialecticsand-difference-against-the-decolonial-turn/.

Woolf, V. 1976. Moments of Being, Falmer: Sussex University Press. 